\title{
RESENHA
}

\section{EDUCOMUNICAÇÃO: REFLEXÃO SOBRE UM CAMPO DE SABER EM MOVIMENTO}

\section{EDUCOMUNICAÇÃO: REFLECTION ON A FIELD OF KNOWLEDGE IN MOVEMENT}

\author{
Avani Maria de Campos Corrêa ${ }^{1}$ \\ Fernando Lopes da Silva ${ }^{2}$ \\ Dra. Diva Souza Silva ${ }^{3}$
}

Obra resenhada: CITELLI, Adílson Odair. COSTA. Maria Cristina Castilho. (Orgs.). Comunicação e educação:implicações contemporâneas.In:Educomunicação: construindo uma nova área do conhecimento.São Paulo: Paulinas, 2011.

O presente texto apresenta-se como sistematização da leitura e análise da obra:Educomunicação: construindo uma nova área do conhecimento. Seus organizadores, Adilson Citelli e Maria Cristina Costa, estão atentos à dinâmica desta nova área que traz consigo uma dimensão ampla e complexa que já conquistou seu espaço. Ao todo, foram apresentados oito artigos nacionais e cinco artigos internacionais, incluindo quatro entrevistas que abordam as nuances da comunicação no ambiente educacional.

\footnotetext{
${ }^{1}$ Graduada em Pedagogia, Especialista em Mídias em Educação e Mestranda em Tecnologia, Educação e Comunicação,da Universidade Federal de Uberlândia. E-mail: avacorrea@ hotmail.com

${ }^{2}$ Especialista em Mídias em Educação e Mestrando em Estudos Literários na Universidade Federal de Uberlândia. E-mail: fernandolopes8@gmail.com

${ }^{3}$ Graduada em Pedagogia, Mestre em Comunicação Social e Doutora em Educação. Professora da Faculdade de Educação e do Programa de Pós Graduação em Tecnologias, Comunicação e Educação da Universidade Federal de Uberlândia. E-mail: diva@faced.ufu.br
} 
Nesta coletânea, os autores expõem suas reflexões e questionamentos sobre o tema em questão, por meio de artigos e entrevistas sobre as "implicações epistemológicas e os desdobramentos entre educação e comunicação, em tempos marcados pela centralidade da comunicação. " (CITELLI, COSTA, 2011, p.08).

No artigo intitulado "Educomunicação: um campo de mediações", Soares (2011) sinaliza que:

Firma-se, principalmente na América Latina, um referencial teórico que sustenta a inter-relação comunicação/educação como campo de diálogo, espaço para o conhecimento crítico e criativo, para a cidadania e a solidariedade. (p.13)

Nesse cenário, percebe-se que existem várias possibilidades de exploração científica da interface entre estas duas áreas. Vale ressaltar que não se trata apenas da junção de dois termos, mas evidenciar o fato de que traz em seu fundamento o desejo de mudanças em prol de práticas pedagógicas inovadoras e democráticas a favor da cidadania.

Outro ponto importante é o fato de que comunicação e educação possam vir a integrar-se, em algum momento, num campo específico e autônomo de intervenção social. Para Soares:

A história nos ensina que tanto a educação quanto a comunicação ao serem instituídas pela 
Escola de Educação Básica (ESEBA) / Universidade Federal de Uberlândia (UFU)

racionalidade moderna, tiveram seus campos de atuação demarcados, no contexto do imaginário social, como espaços independentes, aparentemente neutros, cumprindo funções específicas: a educação administrando a transmissão do saber necessário ao desenvolvimento social e a comunicação responsabilizando-se pela difusão das informações, pelo lazer popular e pela manutenção do sistema produtivo através da publicidade. (SOARES, 2011, p.14).

Esta aproximação foi detectada, no mundo latino, em virtude da contribuição de Célestin Freinet que foi um impulsionador da inter-relação Educação e Comunicação no âmbito escolar. Nos anos 70, surge Paulo Freire como um crítico da educação tradicional. Para Freire (1982, p. 69): "A educação é comunicação, é diálogo, na medida em que não é a transferência de saber, mas um encontro de sujeitos interlocutores que buscam a significação dos significados".

É inegável que para haver conhecimento é imprescindível uma relação dialógica entre os envolvidos para se estabelecer uma prática social transformadora. A concepção Freiriana é que marca esse importante processo de ensino e aprendizagem em termos de dialogicidade. E no presente estudo e reflexão pontuamos que é na gênese da Educomunicação que está contida a concepção dialógica de Paulo Freire. 
Outro artigo que desperta a atenção dos leitores na obra é o intitulado "Comunicação/educação e a construção de nova variável histórica" por Maria Aparecida Baccega (2011) ao definir comunicação/educação como espaço privilegiado da ação dos professores, apresenta-a como lócus na formação dos sentidos sociais. Daí encontra-se, claramente, com base no pensamento da referida autora que "este processo comunicação/educação merece o lugar de segmento prioritário das teorizações e das pesquisas no campo da comunicação, pois permite que se leve em conta, sobretudo, o papel da mídia na configuração da cultura". (BACCEGA, 2011, p.32)

Ora, não se busca aqui um campo de competitividade com as mídias na atualidade. Pode-se inferir que o poder desses veículos de comunicação é imensurável, seja pela sua ação política, seja pela sua forma de manipular, sem controle e, até por contribuições educativas. Baccega (2011), entretanto, chama a atenção ao declarar que o mundo que chega até nós, é editado. Como exemplo tem a TV com sua imagem irreal. A irrealidade, ou virtualidade, faz com que as pessoas subestimem a influência do aparelho.

As escolas estão diante de desafios, provocadas pelas consequentes demandas que trazem em seu bojo. Desafios estes relacionados com as raízes mais profundas na educação e na emergência de novos paradigmas educacionais. Assim, consideramos que a mídia tem que contribuir para a valorização, promoção dos direitos 
humanos e para a diversidade cultural. Este deve ser o seu objetivo principal.

Refletir o papel dos meios de comunicação na educação é o grande desafio aos profissionais e foi discutido com excelência por Roseli Fígaro, no artigo "Estudos de recepção para a crítica da comunicação". A autora propõe uma abordagem diferenciada dos meios de comunicação, e entende que:

Pensar a comunicação a partir da recepção permite entender o papel dos meios de comunicação na vida da sociedade contemporânea, como eles atuam no cotidiano dos grupos sociais, nas diferentes comunidades e culturas. (FÍGARO, 2011.p.91).

Nessa realidade, a escola pode restabelecer seu lugar de importância, desde que, segundo Fígaro (2011): "retome o conhecimento e a formação humanística que ela já forneceu para repensar esseprocesso e a forma como temos abordado os meios de comunicação".(p.94). Analisar o papel da educação neste cenário é fundamental.É importante que os professores estejam atentos e questionem sua prática, pois são mediadores e porque há potencial para isso.

Tais reflexões suscitam a importância das tecnologias no ambiente escolar por não se tratar apenas de uma visão simplista de alterar maneiras tradicionais de ensino para formas inovadoras, isto requer análises sobre como se efetiva essa nova forma de aquisição de conhecimento 
Escola de Educação Básica (ESEBA) / Universidade Federal de Uberlândia (UFU)

acerca desta rede flexível e aberta. Jesús Martín-Barbero no artigo, "Desafios culturais: da comunicação à educomunicação", tece reflexões sobre "os desafios que a Comunicação traz para a Educação quando se pretende a construção da cidadania." (2011,p. 121). O autor entende que essas dificuldades não podem ser deixadas de lado caso se deseje construir a cidadania.

No artigo também disponível nesta obra, intitulado "Comunicação, educação e novas tecnologias: tríade do século XXI", Gomez (2011) resume uma das problemáticas substantivas do novo milênio. Gómez mostra comoas tecnologias aparecem e são orientadas no sentido de políticas voltadas para o mercado e o consumo, menosprezando a lógica dos interesses de cada Estadonação e das diferentes culturas. O autor trata deste tema a partir da racionalidade eficientista e da racionalidade da relevância. Conforme Gómez (2011, p.167):

Dentro dessa mesma racionalidade, que chamo de eficiência, a principal finalidade perseguida pelas autoridades educativas (quase sempre bemintencionadas) é justamente a modernização do sistema educativo. (...) O termo que resume este esforço de incorporação é o da educação à distância.

O referido autor ressalta que a racionalidade da relevância "possível para a incorporação das novas tecnologias à educação" cujo objetivo principal "não estaria no ensino, mas no aprendizado." (Gómez, 2011). Interessante 
Escola de Educação Básica (ESEBA) / Universidade Federal de Uberlândia (UFU)

observar que esta abordagem pressupõe uma transformação do processo ensino-aprendizagem, das interações, da estrutura dos conteúdos, ou seja, da transformação da pedagogia tradicional onde o conteúdo a ser ensinado é feito pelo professor ao aluno. O que difere da nova pedagogia que partiria do educando e do seu contexto. Contudo, é uma abordagem que merece melhor aprofundamento, não alocando na modalidade de ensino em si sua qualificação crítica do processo de ensino e aprendizagem, mas em como é trabalhada e a serviço de quem.

Em tom conclusivo, Goméz (2011) enfatiza a vinculação das novas tecnologias à educação em virtude do cenário do futuro não ser estático. Daí a importância de antecipar o papel que tanto educadores quanto comunicadores devem conquistar, a fim de que a direção e o sentido das inevitáveis transformações sejam as mais relevantes para a sociedade.

Para finalizar, provisoriamente, as reflexões, depreende-se que a relação entre a educação e a comunicação são temas complexos, porém a possibilidade de aprofundamento e desdobramento destas duas áreas é inesgotável. A Educomunicação, além de pesquisar, não se limita a analisar os desafios presentes, trabalha com concepções de educação formal, não formal a partir de ecossistemas comunicativos que é o lócus de ação da mesma. Este novo 
Escola de Educação Básica (ESEBA) / Universidade Federal de Uberlândia (UFU)

campo é interdiscursivo, transdisciplinar e vem se firmando como campo epistemológico entre os estudiosos.

Esta perspectiva faz reconhecer que educação e comunicação caminhando juntas, deixam rastros de novas possibilidades educomunicativas. Para novos tempos, novos olhares, novos meios e consequentemente novas abordagens.

\section{REFERÊNCIAS}

CITELLI, Adílson Odair. COSTA. Maria Cristina Castilho. (Orgs.).Educomunicação:construindo uma nova área do conhecimento.São Paulo: Paulinas, 2011.

FREIRE, Paulo. Extensão ou Comunicação. Rio de Janeiro: Editora Paz e terra, 1982. 